\title{
Investigation of IL-2 and IFN- $\gamma$ to EBV Peptides in Stimulated Whole Blood among Multiple Sclerosis Patients and Healthy Individuals
}

\author{
Nastaran Rafiee ${ }^{a} \quad$ Mehrdad Ravanshad $^{a} \quad$ Bahador Asadi $^{b}$ Roya Kianfara \\ Ali Maleki ${ }^{\mathrm{a}}$ \\ aDepartment of Virology, Faculty of Medical Sciences, Tarbiat Modares University, Tehran, Iran; ${ }^{b}$ Faculty of Medicine, \\ Aja University of Medical Science, Tehran, Iran
}

\section{Keywords}

Epstein-Barr virus · Multiple sclerosis · Interleukin-2 .

Interferon- $\gamma$

\begin{abstract}
Introduction: Epstein-Barr virus (EBV), a double-stranded DNA virus, has 2 phases of lytic and latent infection in host cells. After infecting B lymphocytes, EBV becomes persistent in these cells. In healthy individuals, T lymphocytes play a key role in killing EBV-infected B cells. Statistical studies have shown that symptomatic EBV infection increases the risk of MS. Methods: This study intended to measure the immune system's response against the different components of EBV, focusing particularly on $\mathrm{T}$ lymphocytes' reaction. Consequently, the mRNA level of IL- 2 and IFN- $\gamma$, liable for impressing autoimmune diseases and as indicators of T-cell function, was compared in EBNA1- and BRLF1-treated whole blood (WB) cultures of 10 healthy individuals and $10 \mathrm{MS}$ patients using real-time RT-PCR. Results: The analysis of the results demonstrated a significant increased level of IL-2 in MS patients than healthy subjects after exposure to both peptides. Also, the mRNA level of IFN- $\gamma$ increased in MS patients in EBNA1-treated WB culture. Conclusion: According to the study's results, EBV peptides can reactivate immune cells, es-
\end{abstract}

pecially T lymphocytes, and may indirectly induce inflammation and develop MS; however, it seems that long-time exposure to these peptides has reducing effect on T-cell function and faces the control of infected $B$ lymphocytes with difficulties.

(c) 2021 S. Karger AG, Basel

\section{Introduction}

Human herpesvirus 4, better known as Epstein-Barr virus (EBV), belongs to the family of Herpesviridae [1]. With a circular double-stranded DNA genome, EBV is similar to human chromosome in many molecular facets [2]. EBV infects at least $90 \%$ of all human adults throughout the world [3]. The primary cellular target of EBV is mostly B lymphocytes and epithelial cells, but natural killer (NK) cells and T lymphocytes can also be infected. Ensuing primary infection, EBV sets up a latent infection in memory B cells, while expressing latent genes and stays hidden from the host immune system [4-6]. Latent EBV genomes express 2 latent membrane proteins and $5 \mathrm{EBV}$ encoded nuclear antigens (EBNA); among them, EBNA1 is the only antigen expressed in all 3 forms of latent infection [7].
Correspondence to:

Mehrdad Ravanshad, ravanshad@ modares.ac.ir 
EBV infection can lead to a wide variety of diseases from infectious mononucleosis to EBV-associated malignancies; in addition, many studies have shown a relationship between EBV and autoimmune diseases including multiple sclerosis (MS), a chronic inflammatory disease of the central nervous system, in which myelinated axons are damaged $[3,8]$. In healthy individuals, EBV-specific immune responses, especially $\mathrm{CD}^{+} \mathrm{T}$ cells, control EBV infection by eliminating infected B cells; however, in MS patients, they show progressive exhaustion [9]. Exhausted T cells initially obtain effector function but gently become silenced because of successive $\mathrm{T}$-cell receptor stimulation from persistent antigen [10]. T-cell exhaustion is determined by downregulation of effector function and reduction in type I cytokine secretion such as IL-2 and IFN- $\gamma$ and upregulation of inhibitory molecules [11].

Based on the alteration of EBV-specific T-cell function in MS patients, the aim of the current study was to establish a comparison in immune cell response, after their exposure to EBV peptides. To provide a culture that is physiologically similar to in vivo condition, we used whole blood (WB), a suitable substitute for peripheral blood mononuclear cells (PBMCs), because purification of PBMC using Ficoll results in selective loss of gamma delta $\mathrm{T}$ lymphocytes and other important components impacting cellular response and IFN- $\gamma$ levels $[12,13]$. Furthermore, WB assay is an easy and fast method which sustains the integrity of cellular components of blood and allows different elements to have essential interactions equivalent to in vivo situations $[14,15]$.

\section{Materials and Methods}

\section{Subjects and Sample Processing}

This study used the WB sample from 10 MS patients who were diagnosed with relapsing-remitting multiple sclerosis and also 10 healthy donors (Table 1). The study protocol was approved by the Medical Ethics Committee of Tarbiat Modares University (IR. TMU.REC.1396.704).

Whole venous blood was drawn into an EDTA tube and diluted 1:1 in sterile RPMI 1640 culture medium (BIO-IDEA, Iran). Each blood sample was divided into 3 study groups; 2 of them were treated with $1 \mu \mathrm{g} / \mathrm{mL}$ final concentration of antigen peptide EBV BRLF1 HLA-A*2402 (DYCNVLNKEF) and antigen peptide EBV EBNA1 HLA-B*3501 (HPVGEADYFEY) (JPT Peptide Technologies, Germany), and the last one remained untreated. After $72 \mathrm{~h}$ of incubation, supernatant was collected, and total RNA was extracted using RNSol $\mathrm{H}$ reagent (ROJETechnologies, Iran) according to manufacturer's instruction and stored at $-70^{\circ} \mathrm{C}$. cDNAs were synthesized from extracted RNAs using a cDNA synthesis kit (Biofact, South Korea) pursuant to the kit's protocol and stored at $-20^{\circ} \mathrm{C}$.
Table 1. Characteristics of MS patients and healthy control subjects

\begin{tabular}{lcc}
\hline & MS patients* & $\begin{array}{l}\text { Healthy control } \\
\text { subjects }\end{array}$ \\
\hline $\begin{array}{l}\text { Age, mean (range) } \\
\text { Gender } \\
\quad \text { Female }\end{array}$ & $34(29-44)$ & $33.6(25-51)$ \\
$\quad \begin{array}{l}\text { Male } \\
\text { White blood cell count, mean }\end{array}$ & 6,323 & 6 \\
\hline
\end{tabular}

MS, multiple sclerosis. * All MS patients were diagnosed with relapsing-remitting MS and also took interferon beta as medication.

MTT Assay

MTT (3-[4,5-dimethylhtiazol-2-yl]-2,5-diphenyl-tetrazolium bromide) assay was carried out in accordance with MTT Assay kit (BIO-IDEA) guidelines with a final concentration of $1 \mu \mathrm{g} / \mathrm{mL}$ of each peptide, at $24,48,72$, and $96 \mathrm{~h}$ of cell incubation, and absorbance changes were measured at 570 and $640 \mathrm{~nm}$ using an ELISA plate reader.

\section{Real-Time RT-PCR and Statistical Analysis}

Primers were designed using DNASTAR Lasergene software and synthesized by Metabion (Germany). Real-time reactions were made using RealQ plus 2X Master Mix Green high ROX (Ampliqon, Denmark) according to the manufacturer's instruction. For fluorescent reporter dye, the real-time master mix had SYBR Green. Collected relative gene expression data were analyzed by the $2^{-\Delta \Delta C T}$ (Livak) method, and statistical analyses were performed using GraphPad Prism 8.

\section{Results}

\section{MTT Test Results}

MTT test showed no cytotoxicity of peptides in different hours of cell culture incubation. In Figure 1, cell viability percentage of different groups is illustrated in comparison with WB culture of $24 \mathrm{~h}$. In addition, the viability percentage of treated cells did not significantly differ from the control (untreated) group in each incubation time.

\section{Increase of IL-2 mRNA Levels in MS Patients}

IL-2 mRNA levels of all groups were evaluated by realtime RT-PCR. Results from calculating fold change amount using real-time RT-PCR data were analyzed and charted in Figure 2 by the one-way ANOVA test. The comparison of 4 study group's fold change indicated a remarkable increase in IL-2 mRNA after treating with EBV peptides in MS patients $(p<0.05)$. In both BRLF1- 


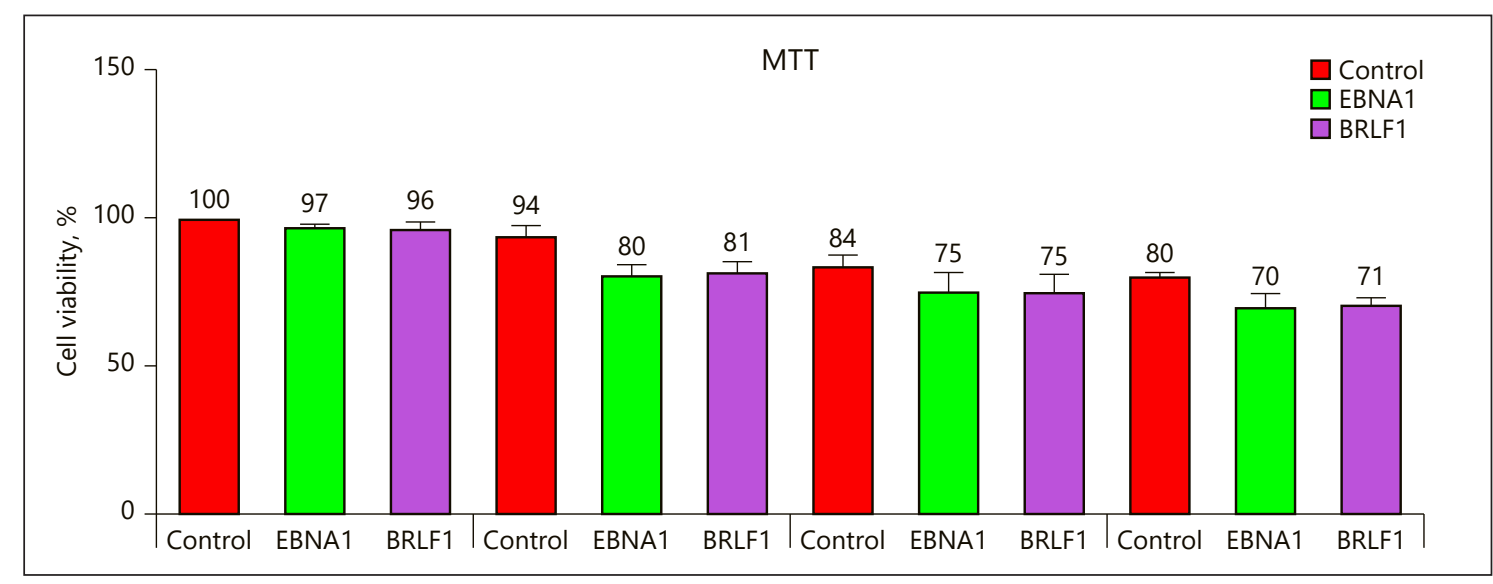

Fig. 1. Cell viability percentage at $24,48,72$, and $96 \mathrm{~h}$ of WB, treated with BRLF1 and EBNA1 peptides. Cell viability shown in every group was in comparison with the first $24 \mathrm{~h}$ and indicated no remarkable difference as well as in comparison with control (untreated) groups. WB, whole blood.

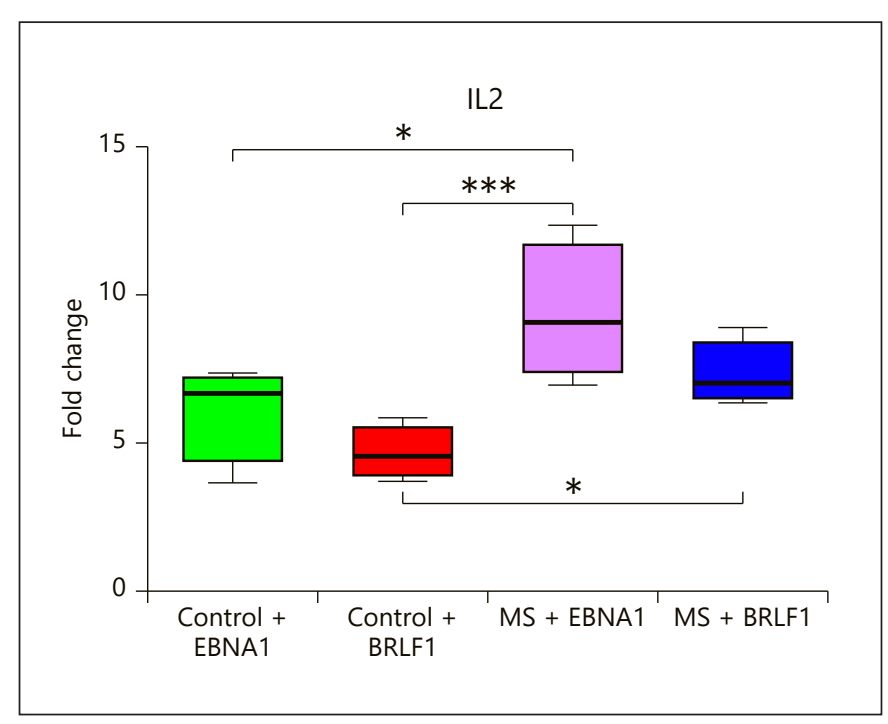

Fig. 2. Tukey's multiple comparisons of IL-2 mRNA levels in healthy individuals and MS patients based on fold change. IL-2 mRNA amount of MS patients was higher in comparison with healthy subjects in both BRLF1- and EBNA1-treated groups $\left({ }^{*} p<\right.$ $0.05,{ }^{* *} p<0.01$, and $\left.{ }^{* * *} p<0.001\right)$. MS, multiple sclerosis.

and EBNA1-treated WB, MS patients had higher IL-2 mRNA amounts, compared to healthy individuals.

\section{Increase of IFN- $\gamma$ Levels after Treating with EBNA1 \\ Peptide in MS Patients}

According to analyzed RT-PCR results by one-way ANOVA (shown in Fig. 3), a notable multiplication of IFN- $\gamma$ mRNA levels $(p<0.05)$ was noticed after treating WB with the EBNA1 peptide in MS patients while there

Investigation of IL- 2 and IFN- $\gamma$ to EBV

Peptides in Multiple Sclerosis Patients

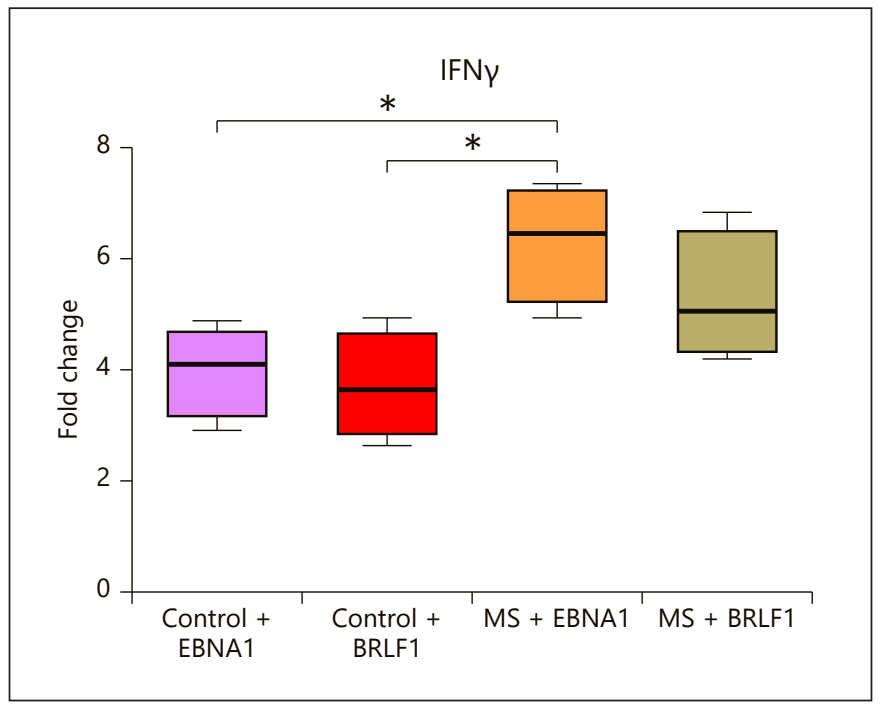

Fig. 3. Tukey's multiple comparisons of IFN- $\gamma$ mRNA levels in MS patients and healthy individuals based on fold change. IFN- $\gamma$ mRNA levels showed a significant increase in EBNA1-treated WB of MS patients $\left(p<0.05^{*}\right)$. MS, multiple sclerosis; WB, whole blood.

was not a considerable increase in the BRLF1-treated group when compared with healthy subjects.

\section{IL-2 mRNA Had Higher Levels in MS EBNA1-Treated Group than IFN- $\gamma$}

Two-way ANOVA test was used to compare IL-2 and IFN- $\gamma$ with each other. As shown in Figure 4, in EBNA1treated WB in MS, IL-2 mRNA demonstrated a higher amount than IFN- $\gamma$. However, a significant difference be- 


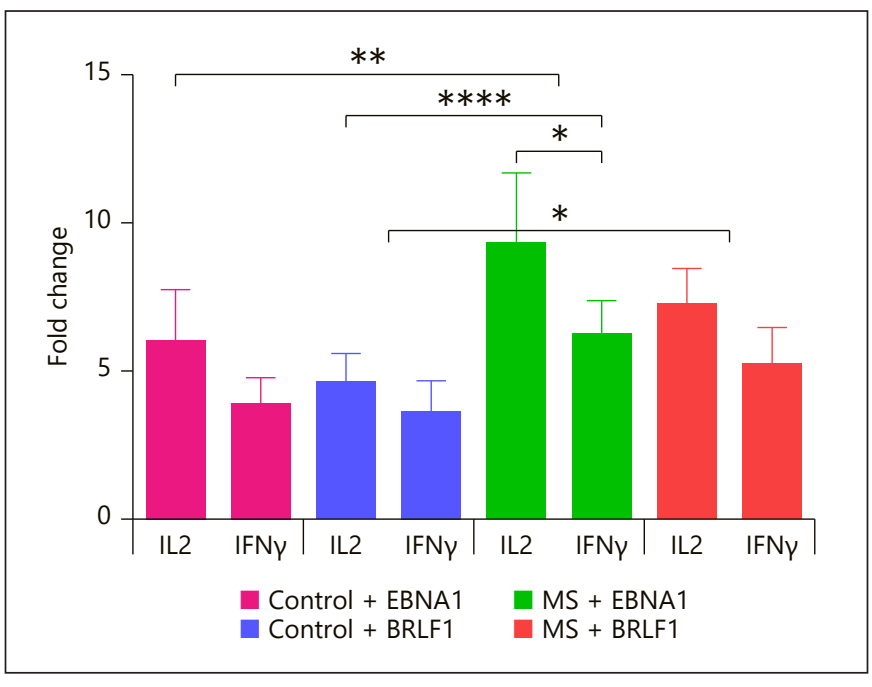

Fig. 4. Sidak's multiple comparisons of IL-2 and IFN- $\gamma$ mRNA levels in study groups. IL-2 showed a higher level of mRNA than IFN- $\gamma$ in EBNA1-treated WB $\left({ }^{*} p<0.05,{ }^{* *} p<0.01,{ }^{* * *} p<0.001\right.$, and $\left.{ }^{* * * *} p<0.0001\right)$. WB, whole blood.

tween IL- 2 and IFN- $\gamma$ in an identical group was only confined to EBNA1-treated WB and could not be observed in any other group.

\section{Discussion}

EBV causes several lymphatic diseases [16]. It usually begins its lytic phase in the tonsils epithelium and expresses latent proteins in naive B cells [17]. In primary infection, infected $\mathrm{B}$ cells are under intense control of $\mathrm{T}$ lymphocytes; however, in latency, EBV becomes hidden from the immune system and remains persistent in resting memory B cells until it becomes activated again [18]. While it is expected to observe higher viral load in reactivated EBV, a study in Qatar surprisingly has reported no significant contrast in different stages of infection. This result implicates the steady activation of EBV regardless of the infection phase [19].

MS is characterized by pervasive myelin attacks due to infiltration of immune cells. Although it was presumed for decades that $\mathrm{CD} 4^{+} \mathrm{T}$ cells solely played a key role in MS development, further studies have revealed the substantial impact of $\mathrm{CD}^{+} \mathrm{T}$ cells in creating the disease [20, 21]. Since symptomatic EBV infection doubles the risk of MS development, this virus is categorized as one of the environmental factors affecting it, and some studies have indicated that immortal EBV-induced B lymphocytes and transformed lymphoblastoid cell lines have a fundamental role in progression of MS [22, 23]. Early studies have found that PBMCs from patients with active MS tend to transform spontaneously into lymphoblastoid cell lines and some express EBV antigens, as well. Later research studies have indicated that the difference between B-cell function in MS patients and healthy subjects is as a result of defective control of $\mathrm{T}$ cells that can be explained by $\mathrm{T}$-cell exhaustion. In addition, molecular homology between some EBV proteins and cell death regulatory proteins hinders apoptosis in infected B cells and gives rise to loss of immune tolerance $[9,17,24]$.

As reported in Figure 2, IL-2 mRNA level in MS patients was significantly higher than healthy subjects after WB treatment with both peptides. This increase illustrates the stimulation of cytokine production by the immune system which is resulting from higher activity of immune cells in MS against EBV antigens. In MS patients with EBV primary infection, $T$ cells that have been reactivated by EBV-infected autoreactive B cells produce IL-2 and other inflammatory cytokines that attack the myelin sheath and cause common autoimmune reactions in MS [25]. In a study executed by Lünemann and colleagues [26], after treating PBMC with EBNA1 antigen, the authors reported an increase in the number of $\mathrm{CD} 4^{+} \mathrm{T}$ cells and the amount of IL-2. Due to similarity between myelin and EBV antigen molecules, $\mathrm{CD} 4^{+} \mathrm{T}$ cells attacked the myelin sheath and contributed to further development of MS.

Figure 3 illustrates a greater mRNA level of IFN- $\gamma$ in EBNA1-treated MS WB, which implies that the IFN- $\gamma$ secreting immune cells of MS patients reactivated only after exposure to a latent antigen. Lünemann et al.'s [26] study has indicated an increased immune response in MS patients toward EBNA1 by evaluating the amount of secreted IFN- $\gamma$. In addition, Jilek and colleagues [27] have stated that EBV-specific $\mathrm{CD} 8^{+} \mathrm{T}$ cells have elevated response in early MS compared to other stages of the disease and other neurological disorders.

In many studies, $\mathrm{EBV}$-specific $\mathrm{CD} 8^{+} \mathrm{T}$-cell response and IFN- $\gamma$ are considerably more powerful in MS patients, although in other studies, $\mathrm{CD} 8^{+} \mathrm{T}$-cell response in MS is reduced or remained unchanged. This inconsistency might be the result of difference in EBV antigens, T-cell population, or MS stages researched by various studies $[9,28]$.

As specified in Figure 4, the cytokine secretion comparison depicts a notable difference between IL-2 and IFN- $\gamma$ in the EBNA1-treated MS group, and that might be the consequence of difference in the quantity of cytokine-secreting immune cells. IL- 2 and IFN- $\gamma$ are substantial factors to appraise $\mathrm{T}$-cell exhaustion. The primary re- 
source for IL- 2 production is activated $\mathrm{CD} 4^{+} \mathrm{T}$ cells although other immune cells such as $\mathrm{CD}^{+} \mathrm{T}$ cell have been reported to produce IL-2 [29-31]. IFN- $\gamma$ is produced by $\mathrm{NK}$ cells, $\mathrm{CD} 4^{+} \mathrm{T}$ helper 1 cells, and $\mathrm{CD}^{+} \mathrm{T}$ cells [32]; however, B cells, NKT cells, and antigen-presenting cells can also secrete IFN- $\gamma$ [33]. Even though IL-2 has a central role in clonal expansion, IFN- $\gamma$ is thought to have influence in differentiation of $\mathrm{CD} 4^{+} \mathrm{T}$ cells into $\mathrm{T}$ helper 1 cells [34]; thus, the greater level of IL-2 might be due to higher number of $\mathrm{CD}^{+}$and $\mathrm{CD} 8^{+} \mathrm{T}$ cells. Moreover, IL-2 promotes effector activities in $\mathrm{CD} 8^{+} \mathrm{T}$ cells by inducing the expression of IFN- $\gamma$ [35]. Therefore, high amount of IL-2 leads to production of IFN- $\gamma$ and enhancement of CD8 ${ }^{+}$T-cell effector activity. Despite Pender's hypothesis, in the present study, increasing level of IL- 2 and IFN- $\gamma$ confirms the elevated activity of immune cells, especially T lymphocytes. These contrasting results might attribute to lengthy stimulation of cell lines whereby exhaustion took place as a consequence of prolonged exposure to EBV antigens, which is not possible in WB culture [9]. Since all of MS patients participated in this study were medicated with interferon beta-1A, it can be inferred that immune cell response was partly suppressed while it could be more intense because IFN- $\beta$, an anti-inflammatory and immune-modulatory cytokine, has antagonistic effect on proinflammatory cytokines especially IFN- $\gamma$. In addition to suppressive effect on IL- 2 and IFN- $\gamma$, IFN- $\beta$ diminishes $\mathrm{T}$-cell activity through the cellular signaling pathway [36, 37].

On account of financial and timing limitations, this study's participants were only restricted to 20 subjects, and real-time RT-PCR was decided as the best option for cytokine evaluation, and thus the focal point of the current study was to establish an easy accessible culture (WB) for assessment of cellular cytokines. In conclusion, addi- tional analysis of blood samples from MS patients with different medication can provide more elaborate information about the correlation between MS-specific drugs and cytokine production. Furthermore, the immune system's reaction to EBV antigenic components in MS will be more clarified by treating WB with other antigenic EBV peptides and evaluation of diverse proinflammatory cytokines.

\section{Statement of Ethics}

The research was directed ethically according to the World Medical Association Declaration of Helsinki. The study subjects have given their written informed consent, and the study protocol was approved by the Medical Ethics Committee of Tarbiat Modares University (IR.TMU.REC.1396.704).

\section{Conflict of Interest Statement}

The authors declare that they have no conflicts of interest.

\section{Funding Sources}

This project was supported by Tarbiat Modares University's grant for Master students of medical virology.

\section{Author Contributions}

Nastaran Rafiee designed and carried out the experiment, analyzed data, and wrote the manuscript. Mehrdad Ravanshad drafted and designed the experiment and supervised the research. Bahador Asadi supervised the research. Roya Kianfar performed the experiment. Ali Maleki performed the experiment and co-wrote the manuscript.

\section{References}

1 Durán AH, Grünewald K, Topf M. Conserved central intraviral protein interactome of the herpesviridae family. mSystems. 2019;4(5): e00295-19.

2 Moquin SA, Thomas S, Whalen S, Warburton A, Fernandez SG, McBride AA, et al. The Epstein-Barr virus episome maneuvers between nuclear chromatin compartments during reactivation. J Virol. 2018;92(3):e01413-17.

3 Dunmire SK, Verghese PS, Balfour HH. Primary Epstein-Barr virus infection. J Clin Virol. 2018;102:84-92.

4 Houldcroft CJ, Kellam P. Host genetics of Epstein-Barr virus infection, latency and disease. Rev Med Virol. 2015;25(2):71-84.
5 Hutt-Fletcher LM. The long and complicated relationship between Epstein-Barr virus and epithelial cells. J Virol. 2017;91(1):e01677-16.

6 Jenson HB. Epstein-Barr virus. Pediatr Rev. 2011;32(9):375-84.

7 Kang MS, Kieff E. Epstein-Barr virus latent genes. Exp Mol Med. 2015;47(1):e131-47.

8 Chen MR. Epstein-barr virus, the immune system, and associated diseases. Front Microbiol. 2011;2:5-10.

9 Pender MP, Csurhes PA, Burrows JM, Burrows SR. Defective T-cell control of EpsteinBarr virus infection in multiple sclerosis. Clin Transl Immunology. 2017;6(1):e126.
10 Catakovic K, Klieser E, Neureiter D, Geisberger R. T cell exhaustion: from pathophysiological basics to tumor immunotherapy. Cell Commun Signal. 2017;15(1):1.

11 Balkhi MY, Ma Q, Ahmad S, Junghans RP. T cell exhaustion and interleukin 2 downregulation. Cytokine. 2015;71(2):339-47.

12 Antas PR, Cardoso FL, Oliveira EB, Gomes PK, Cunha KS, Sarno EN, et al. Whole blood assay to access $\mathrm{T}$ cell-immune responses to mycobacterium tuberculosis antigens in healthy Brazilian individuals. Mem Inst Oswaldo Cruz. 2004;99(1):535.
Investigation of IL- 2 and IFN- $\gamma$ to EBV

Peptides in Multiple Sclerosis Patients
Intervirology 2021;64:203-208

DOI: $10.1159 / 000517002$ 
13 Hartmann SB, Emnéus J, Wolff A, Jungersen G. Revisiting the IFN $-\gamma$ release assay: whole blood or PBMC cultures?: And other factors of influence. J Immunol Methods. 2016;434: 24-31.

14 Pilat C, Krüger K, Frech T, Mooren FC. Exercise-induced cytokine changes in antigen stimulated whole-blood cultures compared to serum. J Immunol Methods. 2017;440:58-66.

15 Silva D, Ponte CG, Hacker MA, Antas PR. A whole blood assay as a simple, broad assessment of cytokines and chemokines to evaluate human immune responses to Mycobacterium tuberculosis antigens. Acta Trop. 2013; 127(2):75-81.

16 Balandraud N, Roudier J. Epstein-Barr virus and rheumatoid arthritis. Joint Bone Spine. 2018;85(2):165-70.

17 Khan G, Hassani A. Epstein-Barr virus in multiple sclerosis. Mult Scler. 2019.

18 Smatti MK, Al-Sadeq DW, Ali NH, Pintus G, Abou-Saleh H, Nasrallah GK. Epstein-Barr virus epidemiology, serology, and genetic variability of LMP-1 oncogene among healthy population: an update. Front Oncol. 2018;8: 211.

19 Smatti MK, Yassine HM, AbuOdeh R, AlMarawani A, Taleb SA, Althani AA, et al. Prevalence and molecular profiling of Epstein Barr virus (EBV) among healthy blood donors from different nationalities in Qatar. PLoS One. 2017;12(12):e0189033.

20 Gross CC, Schulte-Mecklenbeck A, Wiendl H, Marcenaro E, Kerlero de Rosbo N, Uccelli A, et al. Regulatory functions of natural killer cells in multiple sclerosis. Front Immunol. 2016;7:606

21 Salou M, Nicol B, Garcia A, Laplaud DA. Involvement of CD8(+) T Cells in multiple sclerosis. Front Immunol. 2015;6:604.

22 Dobson R, Giovannoni G. Multiple sclerosis: a review. Eur J Neurol. 2019;26(1):27-40.

23 Tracy SI, Kakalacheva K, Lünemann JD, Luzuriaga K, Middeldorp J, Thorley-Lawson DA. Persistence of Epstein-Barr virus in selfreactive memory B cells. J Virol. 2012;86(22): 12330-40.

24 Smatti MK, Cyprian FS, Nasrallah GK, Al Thani AA, Almishal RO, Yassine HM. Viruses and autoimmunity: a review on the potential interaction and molecular mechanisms. Viruses. 2019;11(8):762.

25 Pender MP, Burrows SR. Epstein-Barr virus and multiple sclerosis: potential opportunities for immunotherapy. Clin Exp Immunol. 2014;3(10):e27.

26 Lünemann JD, Jelcić I, Roberts S, Lutterotti A, Tackenberg B, Martin R, et al. EBNA1-specific $\mathrm{T}$ cells from patients with multiple sclerosis cross react with myelin antigens and co-produce IFN-gamma and IL-2. J Exp Med. 2008; 205(8):1763-73.

27 Jilek S, Schluep M, Meylan P, Vingerhoets F, Guignard L, Monney A, et al. Strong EBVspecific CD8+ T-cell response in patients with early multiple sclerosis. Brain. 2008;131(7): 1712-21.

28 Angelini DF, Serafini B, Piras E, Severa M, Coccia EM, Rosicarelli B, et al. Increased $\mathrm{CD} 8+\mathrm{T}$ cell response to Epstein-Barr virus lytic antigens in the active phase of multiple sclerosis. PLoS Pathog. 2013;9(4):e1003220.

29 Ferreira VL, Borba HHL, Bonetti ADF, Leonart L, Pontarolo R. Cytokines and interferons: types and functions. Autoantibodies Cytokines. 2018

30 Liao W, Lin JX, Leonard WJ. IL-2 family cytokines: new insights into the complex roles of IL-2 as a broad regulator of T helper cell differentiation. Curr Opin Immunol. 2011; 23(5):598-604.

31 Nelson BH. IL-2, regulatory T cells, and tolerance. J Immunol. 2004;172(7):3983-8.

32 Green DS, Young HA, Valencia JC. Current prospects of type II interferon $\gamma$ signaling and autoimmunity. J Biol Chem. 2017;292(34): 13925-33.

33 Schroder K, Hertzog PJ, Ravasi T, Hume DA. Interferon- $\gamma$ : an overview of signals, mechanisms and functions. J Leukoc Biol. 2004; 75(2):163-89.

34 Henderson SC, Kamdar MM, Bamezai A. Ly-6A.2 expression regulates antigen-specific $\mathrm{CD} 4+\mathrm{T}$ cell proliferation and cytokine production. J Immunol. 2002;168(1): 118-26.

35 Ross SH, Cantrell DA. Signaling and function of interleukin-2 in T lymphocytes. Annu Rev Immunol. 2018;36:411-33.

36 Milo R, Panitch H. Combination therapy in multiple sclerosis. J Neuroimmunol. 2011; 231(1-2):23-31.

37 Revel M. Interferon- $\beta$ in the treatment of relapsing-remitting multiple sclerosis. Pharmacol Ther. 2003;100(1):49-62. 